\title{
El sistema político de Tailandia. ¿Democracia a golpes?
}

DOI: $10.32870 /$ mycp.v4i12.649

Wendy Díaz Pérez*

$\mathrm{G}$ racias a las estrategias diplomáticas del rey Mongkut y su hijo, el rey Chulalonhkorn en el siglo XIX, Tailandia escapó de la ocupación occidental, si bien no de la administración colonial. Como consecuencia de lo anterior, el Siam ${ }^{1}$ se excluyó de soportar, el menos por un tiempo, la imposición de instituciones occidentales. No tuvo que luchar por su independencia, ni formar partidos políticos o movimientos de masas nacionalistas. En Tailandia continuaron trabajando sus instituciones tradicionales: la monarquía, los clérigos budistas y las burocracias civiles y militares.

A pesar de los varios intentos en el siglo pasado por traer una reforma republicana a Tailandia, las instituciones occidentales, los partidos políticos y las cámaras de representantes siguieron sujetas a la relevancia de las figuras de la monarquía y las burocracias civiles $y$ militares. Estos últimos tomaron el control del país desde 1932.

El rey Mongkut dudaba que la democracia occidental funcionara en una cultura como la del Siam. Mongkut temía, entre otras cosas, que los pobladores del Siam originarios de China tomaran el control de la Cámara de representates en el momento de la presencia de un nuevo sistema político y que los siameses

\footnotetext{
* Investigadora del Departamento de Estudios del Pacífico de la Universidad de Guadalajara.
}

fueran incapaces de adaptarse al pensamiento occidental y a sus instituciones.

A pesar de los esfuerzos del monarca, en 1932 se inauguraron los golpes de Estado en el Siam y los militares llegaron al poder. Ya desde 1912 habían intentado cambiar el sistema político sin éxito. En 1932, en cambio, llegaron al poder e implantaron lo que pocos llamarían una democracia, pues el poder se distribuía únicamente entre ellos. Trajeron, eso sí, la posibilidad de la educación masiva y salud pública, y crearon una monarquía constitucional con el niño-rey Ananda, cuyo primer ministro fue Phraya Phahan.

Desde entonces Tailandia ha visto pasar 16 constituciones distintas en donde se definen las características de su sistema político. Hasta la última versión de 1997, el rey mantiene la soberanía de la nación, pero en el país se ejercen los poderes ejecutivo, legislativo y judicial. La mayoría de las veces la legislatura es una asamblea nacional bicameral: el senado y la cámara de representantes. Los senadores eran designados por el rey a través del primer ministro, aunque esto cambió con la nueva constitución de 1997, en donde se garantiza el que los senadores también sean elegidos mediante elecciones generales.

Si bien el rey es la figura principal del país, su esencial función política consiste en apoyar al primer ministro en turno, y su posición en ello es bastante maleable. Lo anterior le permite 
un juego amplio al primer ministro y a los militares que han estado en el poder en más de dos terceras partes de alrededor de 40 gabinetes existentes desde 1932. Mientras tanto los civiles, con una menor pero creciente preponderancia en la política tailandesa, han tenido que luchar en un escenario sin partidos políticos fuertes, con presiones en los medios de comunicación y de grupos económicos que protegen sus intereses.

Con la caída del gobierno del primer ministro Phrayo Phahon en 1938, los políticos tailandeses entraron en un período de nacionalismo y autoritarismo tras la llegada al poder del coronel Luang Phibun Song Khram, aliado de los japoneses. Luang Phibun, a su vez, caería ante el primer ministro Pridi quien, en cambio, buscaría y mantendría nexos con los aliados. Así, tras la capitulación de Japón en 1945, Tailandia se encontró con un nuevo cuerpo legislativo, la Asamblea General esta vez, con un rol significativo en el gobierno.

Los civiles, por su parte, intentaron restar poder político a los militares y ello provocó inestabilidad durante varios años en Tailandia, cuando en un período de dos años tuvieron cinco primeros ministros distintos.

En 1947 los militares volvieron al poder con un golpe militar más, que se repetiría constantemente como una forma de enfrentamiento entre las distintas facciones militares (la mayoría sin sangre) hasta 1991.

\begin{tabular}{|l|l|}
\hline \multicolumn{2}{|c|}{ REYES DE TAILANDIA $(\mathbf{1 7 8 2 - 2 0 0 1 )}$} \\
\hline Rama I & $1782-1809$ \\
\hline Rama II & $1809-1824$ \\
\hline Rama III & $1824-1851$ \\
\hline Rama IV (Mongkut) & $1851-1868$ \\
\hline Chulalongkorn Rama V & $1868-1910$ \\
\hline Vajiravudh Rama VI & $1910-1925$ \\
\hline Prajadhipok Rama VII & $1925-1934$ \\
\hline Ananda Rama VIII & $1934-1946$ \\
\hline Bhumibol Adulyadej Rama & 1946 a la fecha \\
\hline
\end{tabular}

Según Mark Borthwick, lo que parecería ser un desarrollo político inestable para Tailandia en realidad fue un proceso durante el cual las fuerzas políticas se mantuvieron en un balance dinámico. Esto lo dice porque el sistema parlamentario tailandés si bien era elegido y podía funcionar, en realidad el centro del poder residía en el ejecutivo que a su vez era controlado por las élites militares y grupos burocráticos. Además, el rey seguía siendo una influencia estabilizadora, pues su figura siguió siendo la más reverenciada en Tailandia. Así, el actual rey Bhumibol Adulyadej ha visto pasar a los distintos gabinetes sin involucrarse aparentemente en los asuntos políticos, aunque su apoyo al régimen en el poder es indispensable para su sobrevivencia.
Primeros ministros en Tailandia (2000-1932)

\begin{tabular}{|l|l|l|}
\hline Chuan Leeknai & Kittikachorn & Pholphavuhasena \\
\hline General Chavalit Yongchaiyudh & Field Marshal Sarit Thanarat & General Praya Phahol \\
\hline Banharn Silpa-Archa & Field Marshal Thanom & Pholphayuhasena \\
\hline Chuan Leeknai & Kittikachorn & General Prava Phahol \\
\hline Anand Panvarachun & Mr. Pochana Sarasin & Pholphavuhasena \\
\hline General Chatichai Choonhavan & Field Marshal p. Pibulsongkram & General Prava Phahol \\
\hline General Prem Tinsulanonda & Major Khuang Apivongse & Pholphayuhasena \\
\hline General Kriengsak Chamanand & Rear Admiral Thavan & General Prava Phahol \\
\hline Dr. Tanin Kraivixian & Thamronfnavasawat & Pholnhavuhasena \\
\hline M.R. Seni Pramoj & Rear Admirar Thavan & Phrava Manopakorn Nititada \\
\hline M.R. Kukrit Pramoj & Thamrongnavasawat & \\
\hline M.R. SeniPramoi & Dr.Pridi Banomvong & \\
\hline Professor Sanva Dharmasakti & Maior Khuang Apivongse & \\
\hline Field Marshal Thanom & MR Seni Pramoj & \\
\hline Kirrikachorn & Tawee Boonvaket & \\
\hline Field Marshal Thanom & Major Khuang Apivongse & \\
\hline Kittikachorn & Field MarshalPibulsongkram & \\
\hline Field Marshal Thanom & General Phrava Phahol & \\
\hline
\end{tabular}

A partir de 1975 Tailandia inauguró su transición democrática. En estos años, un movimiento de estudiantes forzó al gobierno a tener elecciones populares a través de partidos políticos con registro. Desde entonces, el poder se ha alternado entre los militares y civiles.

Durante la 
década de los ochenta vino un período de aparente estabilidad en la que antiguos militares convertidos en civiles (y hombres de negocios) llegaron al poder. De esta forma, Prem Tinsulanonda se colocó como primer ministro durante ocho años. Su período terminó con lo que se ha llamado las primeras elecciones verdaderamente democráticas de Tailandia, de donde llegó al poder el ex general Chatichai Choonhavan. Al mismo tiempo líderes empresariales y miembros del parlamento incrementaron su cuota política.

Sin embargo, los esfuerzos de los grupos civiles se vinieron abajo con un nuevo golpe de Estado el 23 de febrero de 1991. Esta vez, el comandante supremo general Sunthorn Kongsompong y el general Suchina Kraprayoon intentaron quedarse en el poder. Estados Unidos, no obstante, no estuvo de acuerdo con esta acción y suspendió la ayuda a Tailandia. Así, el rey Bhumibol se vio obligado a no apoyar al nuevo régimen y se nombró a Anand Panyarachun como primer ministro interino.

En 1997 Tailandia aprobó una nueva constitución cuyas reformas principales se resumen en:

a) Cambios en el sistema para promover la honestidad entre los políticos, erradicar prácticas corruptas y empleo de dinero en los procesos electorales. ${ }^{2}$

b) Reconocimiento al derecho de asamblea y garantía a los derechos y libertades individuales.

c) Rendición de cuentas para asegurar la transparencia en los manejos administrativos.

d) Reforzamiento de la participación popular en las administraciones locales.

e) Elección de los miembros del Senado.

f) Obligación de los miembros del Parlamento de renunciar a su cargo cuando sean designados miembros del gabinete. ${ }^{3}$
Con una nueva constitución y elecciones, el general Suchinda se estrenó como primer ministro. Sin embargo, tras una serie de manifestaciones civiles en oposición al régimen de coalición, en donde murieron más de 50 personas, Suchinda renunció y Anand fue restaurado.

En 1992 el Partido Demócrata gana en las elecciones y obtiene la mayoría de los asientos de la legislatura. Su líder y nuevo primer ministro, Chuan Leekpai, encabeza una nueva coalición con otros partidos. Leekpai se mantuvo como primer ministro hasta las elecciones de 1996, calificadas como las más corruptas en la historia del Siam.

Ninguno de los tres ministros que transitaron por el gobierno de Tailandia en el período de 1991 a 1997 pudo completar su período constitucional. Y ésta ha sido la constante en la historia política del antiguo Siam. De hecho, como se puede constatar en el cuadro, en promedio cada primer ministro se mantiene sólo 17 meses en el poder.

Debido a su pobre desarrollo democrático, en general los partidos políticos en Tailandia pueden calificarse como débiles. Se constituyen como aglomeraciones de facciones, y carecen de una ideología común. Sin embargo, en los últimos años, a pesar de las contradicciones de la democracia tailandesa, como sostiene Guadalupe Ibarra, "ésta ha demostrado una acelerada liberalización", 4 gracias a la incorporación de diversos grupos sociales influyentes en la política. Es el caso de los llamados Chao Pho, grupo económico y político de provincia al cual le han dado como sobrenombre "Padrinos, S. A." y al que pertenecía el ex primer ministro Banhar.

Los Chao Sua conforman otro grupo económico-político compuesto por magnates empresariales, de donde proviene el recién nombrado primer ministro Thaksin Shinawatra, de 
51 años, de orígen étnico chino (el gran temor del rey Mongkut), y dueño de un grupo de empresas que entre otras cosas mantiene el monopolio de los operadores de telefonía celular en el país, a través de la empresa Advanced Information Services.

En las elecciones del 6 enero de 2001 compitieron justamente las cabezas de estos dos grupos: Chuan Leekpai y Thaksin Shinawatra. Thaksin Shinawatra llegó al poder en medio de serias acusaciones de corrupción. La Comisión Nacional contra la Corrupción lo acusó formalmente en diciembre pasado de una posible evasión de impuestos, por transferir sus bienes a sus empleados y familiares. La acusación llegó a la Corte Constitucional que resolverá después de la última semana de mayo. Si resultara positivo, Shinawatra quedaría inhabilitado por cinco años para ocupar cargos públicos.

Hace unos días, el rumor sobre la posible nueva designación como primer ministro de personas cercanas a Shinawatra apuntaban hacia el ministro del Interior, Purachai Piumsombun, y el ministro de Finanzas, Somkid Jatusripitak, ambos miembros del Thai Rak Thai, partido político creado por Shinawatra hace dos años para llegar al poder. Cualquiera de los dos, según Rodney Tasker ${ }^{5}$, garantizaría la continuidad del proyecto económico de Shinawatra.

Con instituciones democráticas débiles, las predicciones del rey (Mongkut hace más de cien años) no se equivocaron del todo. Siam no estaba preparado para aceptar las ideas occidentales, y aún carece de suficiente cultura política para lograrlo. Y, quizás lo más alarmante para los originarios del Siam, las élites de origen chino llegaron con Thaksin, y las fuerzas occidentales, con el Fondo Monetario Internacional, finalmente llegaron al poder.

\section{Fuentes}

BORTHWICK Mark. Pacific Century, The Emergence of Modern Pacific Asia. Westview Press, 1992, 590 pp; LEIPZIGER, Danny, Vinod Thomas. Experiencia de Asia Oriental. Banco Mundial, 1993, 43 pp; VERA, Simone, Anne Thompon. The Asian Pacific Political and Economic Development in a Global Context. EU: Longman Publishers, 1995, 418 pp; SOMRÜDEE Nicro. "Thailand's NIC
Democracy: Studying from General Elections", en Pacific Affairs, vol. 66, núm.2, Canadá 1993; pp. 167-182 ECCLESTON Bernard, Michael Dawson y Deborah Mc Namara. The Asia Pacific Profile. Landonand NY, 1998, 383 pp; IBARRA Guadalupe. "Tailandia a finales del siglo XX. La dinámica de una democracia parlamentaria giratoria y su desarrollo tras la crisis asiática", en Asia Pacífico 2000. Programa de Estudios APEC. Centro de Estudios de Asia y África. México, El Colegio de México, 2000; ROMERO Marcela. "Tailandia”, en Asia Pacífico 1998. Programa de Estudios APEC, Centro de Estudios de Asia y África. México, El Colegio de México, 1999, pp. 373395; ESCALONA Agüero Alejandro. "Tailandia" en Asia Pacífico 1997. Programa de Estudios APEC. Centro de Estudios de Asia y África. México, El Colegio de México, 1997, pp. 397-342; TOLEDO Daniel. "Tailandia”, en Asia Pacífico 1995. Programa de Estudios APEC. Centro de Estudios de Asia y África. México, El Colegio de México, 1995, pp. 413-449; TOLEDO Daniel. “Tailandia” en Asia Pacífico 1993. Programa de Estudios APEC. Centro de Estudios de Asia y África. México, El Colegio de México, 1993, pp. 274-304.

FAR EASTERN ECONOMIC REVIEW, 15 de marzo 2001. FAR EASTERN ECONOMIC REVIEW, febrero 22, 2001. FAR EASTERN ECONOMIC REVIEW enero 18, 2001. FAR EASTERN ECONOMIC REVIEW noviembre 30, 2000. FAR EASTERN ECONOMIC REVIEW noviembre 2, 2000. FAR EASTERN ECONOMIC REVIEW, agosto 31, 2000. FAR EASTERN ECONOMIC REVIEW, junio 15, 2000. FAR EASTERN ECONOMIC REVIEW, junio1, 2000.

FAREASTERN ECONOMIC REVIEW, septiembre 30, 1999.

\section{Notas}

1 Siam cambió su nombre por el de Tailandia en 1939. En este trabajo utilizaré indistintamente ambos nombres para referirme al Reino de Tailandia, actual nombre oficial.

2 La corrupción es uno de los grandes problemas de la sociedad tai. Tailandia ocupa el lugar número 60 en transparencia $v s$ corrupción en un estudio en 90 países. Su calificación es de 3.2 sobre 10. México, por su parte, ocupa el lugar 59 con 3.3 de calificación. El indicador anterior es resultado de un estudio realizado por la Goettingen University y Transparency International que tratan de medir las percepciones del grado de corrupción de un país calificado por hombres de negocios, analistas de riesgo y público en general (Internet Center for Corruption Research, www.gwdg.de/»vw/icr.htm).

3 Marcela Romero García, "Tailandia" en Asia Pacífico 1998. Programa de Estudios APEC, Centro de Estudios de Asia y África. El Colegio de México, 1999, p. 383.

4 Guadalupe Ibarra Kurka, "Tailandia a finales del siglo XX. La dinámica de una democracia parlamentaria giratoria y su desarrollo tras la crisis asiática”, enAsia Pacífico 2000. Programa de Estudios APEC. Centro de Estudios de Asia y Africa, El Colegio de México, 2000, p. 428.

5 Rodney Tasker, “Thaksin is Big. Is Thailand Bigger?", en Far Eastern Economic Review, 31 de mayo 2001.

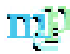

